WellBeing International

WBI Studies Repository

$1-2015$

\title{
"Goats That Stare at Men" - Dwarf Goats Alter Their Behaviour in Response to Human Head Orientation But Do Not Spontaneously Use Head Direction as a Cue in a Food-Related Context
}

\author{
Christian Nawroth \\ Martin Luther Universitat Halle-Wittenberg \\ Eberhard von Borell \\ Martin Luther Universitat Halle-Wittenberg \\ Jan Langbein \\ Leibniz Institute for Farm Animal Biology
}

Follow this and additional works at: https://www.wellbeingintlstudiesrepository.org/soccog

Part of the Animal Studies Commons, Comparative Psychology Commons, and the Other Animal Sciences Commons

\section{Recommended Citation}

Nawroth, C., von Borell, E., \& Langbein, J. (2015). 'Goats that stare at men': dwarf goats alter their behaviour in response to human head orientation, but do not spontaneously use head direction as a cue in a food-related context. Animal cognition, 18(1), 65-73.

This material is brought to you for free and open access by WellBeing International. It has been accepted for inclusion by an authorized administrator of the WBI Studies Repository. For more information, please contact wbisr-info@wellbeingintl.org.

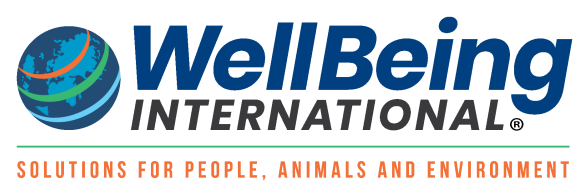


1 “Goats that stare at men" - Dwarf goats alter their behaviour in

2 response to human head orientation but do not spontaneously use

3 head direction as a cue in a food-related context

4 Christian Nawroth ${ }^{1}$, Eberhard von Borell ${ }^{1}$, Jan Langbein $*^{2}$

$5{ }^{1}$ Department of Animal Husbandry \& Ecology, Institute of Agricultural and Nutritional Sciences,

6 Martin-Luther-University, Halle, GER

$7{ }^{2}$ Institute of Behavioural Physiology, Leibniz Institute for Farm Animal Biology, Dummerstorf,

$8 \quad G E R$

9

10

11

12

13 Corresponding author

14 Jan Langbein

15 Institute of Behavioural Physiology

16 Leibniz Institute for Farm Animal Biology

17 Dummerstorf, GER

18 Phone: +49-38208-68814

19 Fax: +49-38208-68801

20 Email address: langbein@fbn-dummerstorf.de

21 
Recently, comparative research on the mechanisms and species-specific adaptive values of attributing attentive states and using communicative cues has gained increased interest, particularly in non-human primates, birds, and dogs. Here, we investigate these phenomena in a farm animal species, the dwarf goat (Capra aegagrus hircus). In the first experiment, we investigated the effects of different human head and body orientations, as well as human experimenter presence/absence, of

29 a human on the behaviour of goats in a food-anticipating paradigm. Over a 30-sec interval, the experimenter engaged in one of four different postures or behaviours (head and body towards the subject, head to the side, head and body away from the subject, or leaving the room) before delivering a reward. We found that the level of subjects' active anticipatory behaviour was highest in the control condition and decreased with a decreasing level of attention paid to the subject by the experimenter. Additionally, goats 'stared' (i.e., stood alert) at the experimental setup for significantly more time when the experimenter was present but paid less attention to the subject ('Head' and 'Back' condition) than in the 'Control' and 'Out' conditions. In a second experiment, the experimenter provided different human-given cues that indicated the location of a hidden food reward in a two-way object choice task. Goats were able to use both 'Touch' and 'Point' cues to infer the correct location of the reward but did not perform above the level expected by chance in the 'Head only' condition. We conclude that goats are able to differentiate among different body postures of a human, including head orientation; however, despite their success at using multiple physical human cues, they fail to spontaneously use human head direction as a cue in a food-related context. cues 
Introduction

Over the last decade, research on the attribution of attentive states and the use of communicative

51

cues has provided insight into the complex social lives of non-human animals, particularly primates, birds, and dogs. In addition to comparative reasons, it is important to know to what extent nonhuman individuals understand the perceptual and mental states of others and the context in which this knowledge is used (Gómez 2005a; Rosati and Hare 2009; Davidson et al. 2014).

The ability to recognise different attentive states of con- or heterospecifics may yield adaptive advantages in the contexts of predation, deception or cooperation; for example, individuals may benefit from knowing if others are observing them. Two types of test paradigms are commonly used to study the recognition of attentive states. The first is a choice paradigm in which a subject must choose between two individuals that differ in their attentive state towards the subject to receive a reward. Subjects can either avoid being observed by choosing the non-attentive person (competitive context: Flombaum and Santos 2005; Sandel et al. 2011) or the person paying them attention (communicative context: Povinelli and Eddy 1996; Gácsi et al. 2004; Bulloch et al. 2008; Proops and McComb 2010; Botting et al. 2011; Bania and Stromberg 2013; Nawroth et al. 2013a) expecting to receive a food reward with less delay. The second is a food-requesting paradigm in which the subject faces a human experimenter who engages in different attentive states before a reward is delivered after some delay (Kaminski et al. 2004; Hattori et al. 2007; Tempelmann et al. 2011; Maille et al. 2012; Bourjade et al. 2014). The latter paradigm has been applied to primate species, with the behavioural analysis focusing on specific behavioural patterns. These patterns may include the amount and duration of trained begging gestures (Kaminski et al. 2004; Maille et al. 2012; Bourjade et al. 2014) , the extent of gazing or alternated gazes directed towards the experimenter's face (Hattori et al. 2007; Bourjade et al. 2014) and/or intentional attempts to regain the attention of another subject (Bourjade et al. 2014), all depending on the attentive state of a human experimenter. However, general behaviour patterns, such as anticipatory behaviour, have 
been rarely examined.

Although the ability to recognise another individual is observing one has adaptive advantages, the ability to follow the gaze of others may also be crucial to survival in some circumstances. At least three different mechanisms can be classified: Gaze following, geometrical gaze following and shared attention. Gaze following is defined as the co-orientation of one's own gaze direction into distant space with that of another individual (Tomasello et al. 1998; Kaminski et al. 2005; Wilkinson et al. 2010; Loretto et al. 2010). However, a learned association or a simple behavioural response cannot be excluded as explanatory factors. In turn, geometric gaze following enables a subject to follow the gaze of a con- or hetero-specific around barriers, which requires taking the visual perspective of the other individual (Bugnyar et al. 2004; Bräuer et al. 2005; Range and Virányi 2011). Another mechanism of co-orienting with another individual's gaze direction is to share attention with the other individual towards the focal object. This latter mechanism is commonly investigated using a so-called object choice task. Here, a subject chooses between two or more containers, one of which covers a hidden food reward. Typically, a human experimenter administers a communicative cue (e.g. pointing or gazing) towards the food-containing container, and the tested subject is free to choose one (for a review see Miklósi and Soproni 2006). For example, dogs have been shown to be exceptionally skilled at comprehending human-given cues such as different forms of pointing gestures or gaze direction (Hare et al. 2002; Hare and Tomasello 2005; but see Udell et al. 2008). Other domesticated species, such as goats (Kaminski et al. 2005) and horses (Maros et al. 2008; Proops et al. 2010), appear to be able to make use of some pointing gestures comprehended by dogs, but fail to utilise gaze cues of a human experimenter to find a reward. In addition, some non-domesticated species have been found capable of following humangiven cues, including gaze direction (e.g., grey parrots: Giret et al. 2009; rooks: Schmidt et al. 2011; seals: Scheumann and Call 2004).

In previous research, Kaminski and colleagues (2005) showed that goats can follow the gaze of conspecifics into distant space. They also showed that goats fail to use the head direction of a 
human to find hidden food in an object-choice task, despite their success in using pointing and touch cues. This negative result may reflect the incapacity of goats to use head direction as a communicative cue. However, this result could also be due to methodological issues, for example, an out-of-focus or out-of-sight cue (Mulcahy and Hedge 2012; Nawroth et al. 2014b).

In this study, we analysed the behaviour of subjects presented with hidden food with 1) no need to use the orientation of the experimenter's head or body to infer the location of the reward (Experiment 1) and 2) the need to interpret the physical cues, body or head orientation to infer the location of the reward(Experiment 2). In the first experiment with dwarf goats, we employed an experimental design similar to the food-requesting paradigm that has been primarily used with primates (Kaminski et al. 2004; Tempelmann et al. 2011; Maille et al. 2012; Bourjade et al. 2014). As the goats were not trained to exhibit specific begging behaviour, we refer to our paradigm as a food-anticipation paradigm, according to the measured behavioural parameters. We analysed the behaviour goats' exhibited towards the experimenter and the experimental setup in response to different head and body postures as well as the presence and absence of the experimenter over a 30sec period. Because subjects had not been trained to produce begging gestures, we focused on more general behavioural patterns; specifically, different types of anticipatory behaviour . Anticipatory behaviour was described by Craig (1918) as arousal with goal-directed activity that occurs during the appetitive phase, during which the actual reward is not yet available and/or visible. One of the main characteristics of anticipation is enhanced attention which is reported to be characterised by increases in activity and exploratory behaviour alternating with phases of standing alert and watching (Bolles 1968; Hooks et al. 1994; Hansen and Jeppesen 2006; Zimmerman et al. 2011; Imfeld-Mueller and Hillmann 2012; Moe et al. 2012). Importantly, anticipation requires the ability to internally represent expectations of a forthcoming reward during the appetitive phase (Spruijt et al. 2001). We therefore predicted that the time subjects spent spend engaging in anticipation behaviours would depend on their perceived likelihood of reward delivery. In general, when the experimenter is present and looking at the subject, anticipatory behaviour should be higher than 
126 when the experimenter is absent and therefore unable to deliver the reward. In contrast, we would 127 expect a higher level of standing alert, although not full arousal, i.e., close watching and 128 observation of the experimental setup, when the possibility of immediate reward delivery is likely 129 but not certain; e.g., when the experimenter is present but not focused on the subject. Immediately 130 following, we conducted a second experiment in which we administered different human-given 131 cues to the subjects to find a hidden food reward using a very similar object-choice paradigm to 132 that used by Kaminski and colleagues (2005), with some modifications. We hypothesised that goats 133 should be able to use physical cues, such as pointing or touching, due to local enhancement or 134 learning effects. These effects are absent when only head direction is available as a communicative 135 cue. Therefore, goats should perform at a level equal to chance at sharing attention with other 136 individuals when only head cues are available, as there is no strong adaptive need for this ability 137 due to goats' abundantly distributed, natural food sources. 


\section{Materials \& Methods}

140

\section{Ethics statement}

All procedures involving animal handling and treatment were approved by the Committee for Animal Use and Care of the Ministry of Agriculture, Environment and Consumer Protection of the federal state of Mecklenburg-Vorpommern, Germany (Ref. Nr. 7221.32.1-014/13). Housing facilities met the German welfare requirements for farm animals.

\section{Subjects, housing and general procedure}

Eleven female Nigerian dwarf goats (Capra aegagrus hircus), aged 3-4.5 years, participated in both experiments. Goats were group-housed at the Leibniz Institute for Farm Animal Biology. The pen contained straw bedding and was equipped with an automatic waterer, a hayrack, a round feeder for delivering commercial concentrate and a wooden rack for climbing. The goats had ad libitum access to hay, and concentrate was offered twice daily at $300 \mathrm{~g} / \mathrm{d} / \mathrm{animal}$. Subjects were not food restricted before testing. The subjects were tested daily from 9:00-12:00 and 14:00-17:00 in April 2013. For training and testing, individual goats were physically and visually separated from their pen-mates in an adjacent compartment next to their home pen $(150 \mathrm{~cm} \times 125 \mathrm{~cm})$. The experimenter sat in another adjacent compartment separated from the test animal by a grate, allowing subjects to insert their snouts through the bars. A sliding board $(60 \mathrm{~cm} \times 25 \mathrm{~cm})$ was placed on a small table at a height of approximately $35 \mathrm{~cm}$ in front of the grate. In the test and motivation trials, one or two dark brown bowls (diameter: $14 \mathrm{~cm}$ ), depending on the experiment, were placed on the board. Dark brown cups (diameter: $11 \mathrm{~cm}$; height: $10 \mathrm{~cm}$ ) covered the bowls. The distance between the bowls and the subject was approximately $30 \mathrm{~cm}$. Goats had previously participated in a study (Nawroth et al. 2014a) of a similar test design (i.e., an object-choice task) and were therefore familiar with the 
165

166

167

168

169

170

171

172

173

174

general procedure; that they had to place their snout through the bars to indicate their choice and to receive a reward.

\section{Experiment 1}

One training session was conducted the day before testing began. The experimenter put a food reward (a piece of pasta) - visible for the goat - in a bowl that was placed in the middle of the sliding board and covered it with a cup. The experimenter then pushed the board forward. After the subject snouted through the middle gap of the grate, the experimenter uncovered the reward and gave it to the subject. This was repeated ten times for each subject. After the training trials, all individuals were familiar with the procedure and reliably chose the bowl when the board was pushed forward. The procedure used in the test trials was similar, except that after the experimenter had baited the cup, the subjects had to wait 30 seconds to receive the reward. During this time, the experimenter engaged in one of four conditions (Figure $1 \mathrm{a}-\mathrm{d}$ ):

Control: the experimenter sat motionless with his head oriented towards the subject

Head: $\quad$ the experimenter sat motionless with his head oriented to the right

Back: $\quad$ the experimenter sat motionless with his back to the subject

Out: $\quad$ the experimenter left the test pen

Before each test trial, subjects received a training trial for motivational reasons. Subjects received a total of four sessions of sixteen trials (two test trials for each condition and eight training trials) and therefore a total of eight trials per condition. Conditions were presented pseudorandomly with the restriction that the same condition was never presented twice in a row. 

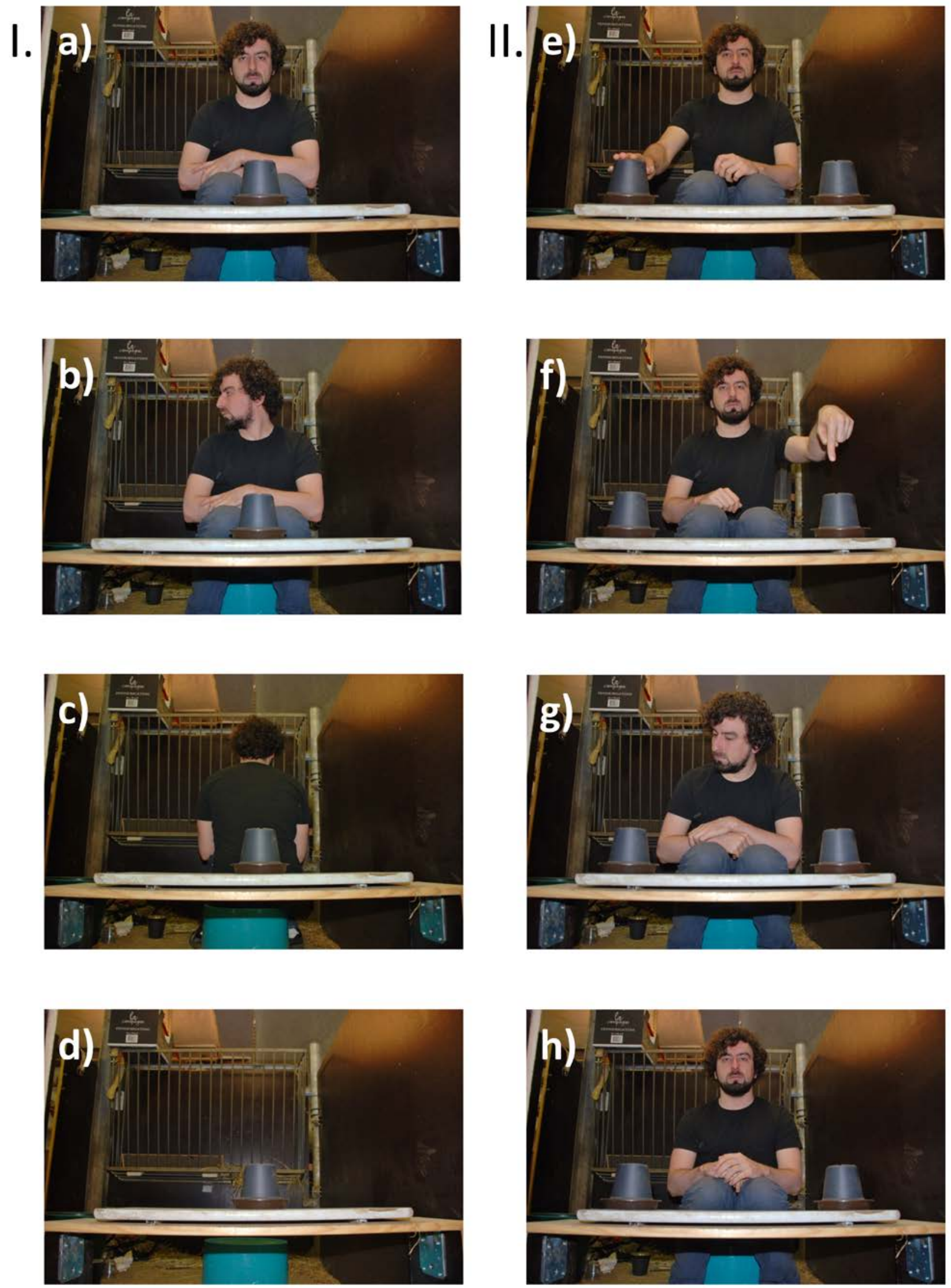

191 Figure 1 I. Conditions in Experiment 1 a) Control b) Head c) Back d) Out II. Conditions in 192 Experiment 2 e) Touch f) Point g) Gaze h) Control 


\section{Data coding and statistical analysis}

Goat behaviour was video-recorded (Panasonic WV-CP500, Tamron 13VG2811ASIR-SQ lens,

EverFocus EDRHD-4H4 HDcctv Hybrid DVR). For Experiment 1, we used the videos to record the total amount of time the subject was oriented towards the grate during the 30-sec delay of each trial (assuming that the subject was paying attention to the experimenter and/or the experimental setup) and engaged in a) active anticipatory behaviour (i.e., nervous tripping near the grate while repeatedly snouting through the bars; see supplementary material, video S1) and b) standing alert

202 (i.e., standing motionless with an extended neck near the grate, observing the experimental setup; see supplementary material, video S2). For behavioural coding, we used The Observer 10.1 (Noldus Information Technology, Wageningen, Netherlands). Both behaviours were modelled using linear mixed models (PROC Mixed, SAS® 9.2) to analyse the effects of 'condition', 'half' (i.e., first or second half of trials per condition) and their interaction. Each animal was defined as the subject for the repeated statement and was included with all fixed factors in both models. Least square means (LSM) and their standard errors (SE) were calculated. For pairwise comparisons (post-hoc analysis), adjustments for repeated testing were applied (Tukey-Kramer corrections). Additionally, we scored the number of vocalization of all individuals across conditions.

\section{Results}

In Experiment 1, two subjects interfered with the setup (kicking at the sliding board) during the test trials and were therefore excluded. We found a significant effect of 'condition' (Figure 2; $F_{3,272}=$ 86.79; $P<0.001)$, but not of either 'half' $\left(F_{1,272}=1.44 ; P=0.23\right)$ or the interaction between the two variables $\left(F_{1,272}=1.94 ; P=0.12\right)$, on active anticipatory behaviour. Post-hoc analysis revealed that active anticipatory behaviour decreased across the conditions with decreasing attention of the 
experimenter towards the goats (all $P<0.02$ ). For standing alert, we found an effect of 'condition'

220 (Figure 2; $\left.F_{3,272}=16.87 ; P<0.001\right)$, but not of either 'half' $\left(F_{7,272}=1.30 ; P=0.256\right)$ or the 221 interaction between the two variables $\left(F_{7,272}=1.15 ; P=0.33\right)$. Subjects were significantly less 222 likely to stand alert in the 'Control' and 'Out' conditions than in the 'Head' and 'Back' conditions 223 (post-hoc analysis; all $P<0.01$ ). Only two subjects vocalized during the test trials. One of these 224 rarely vocalised in any condition (Control: 1; Head: 0, Back: 0; Out: 2). Vocalisation of the second 225 subject increased across the conditions with decreasing attention of the experimenter towards the 226 subject (Control: 3, Head: 10, Back: 17; Out: 36).

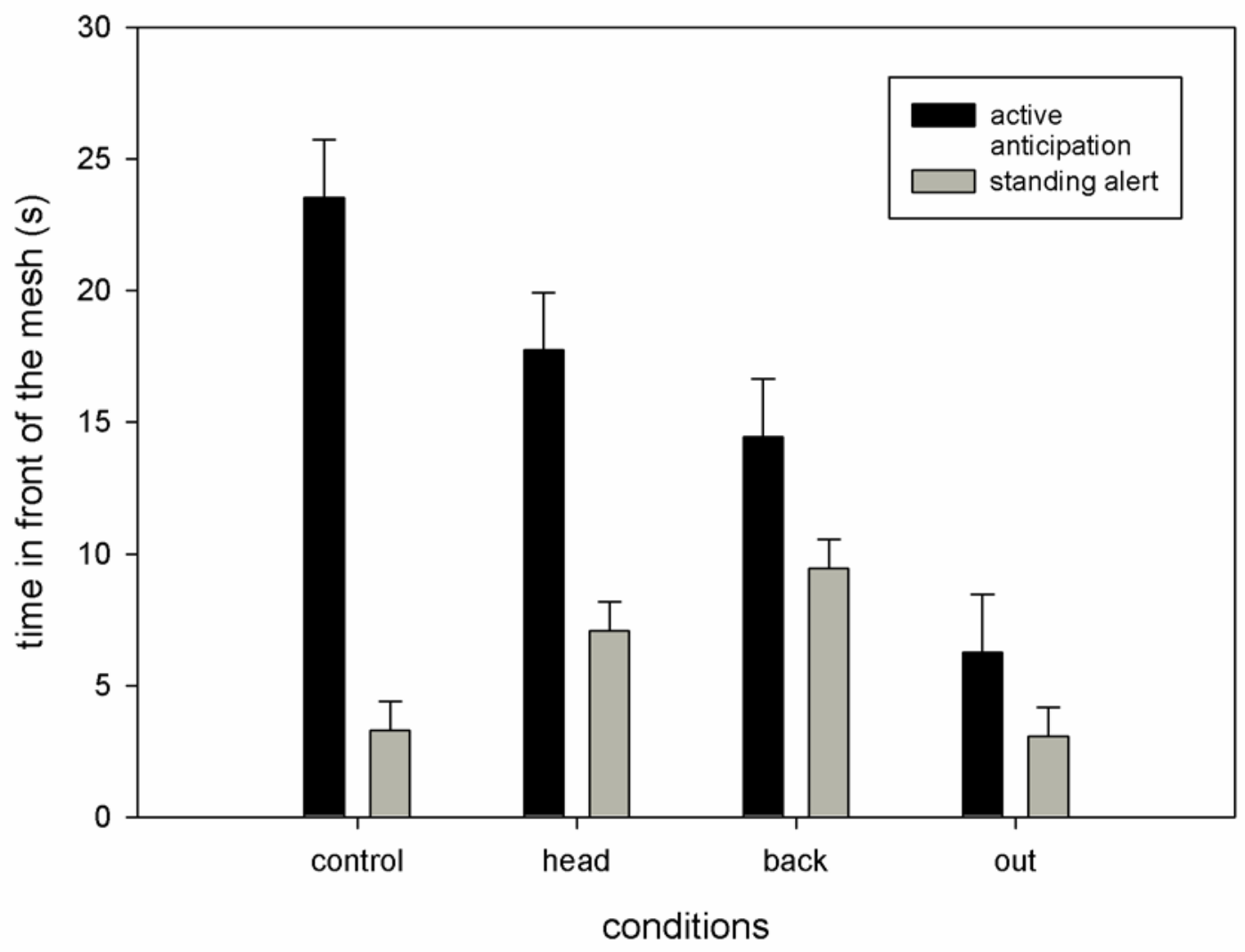

Figure $\quad 2$

229 Results of Experiment 1. Graph shows the amount of time subjects engaged in active anticipatory 230 behaviour (grey bars) and standing alert (white bars) during the 30-sec interval of each trial (LSM \pm 231 SE). 


\section{Experiment 2}

236 Two bowls were placed $35 \mathrm{~cm}$ apart on the sliding board; the experimenter remained in the same 237 position as in Experiment 1. At the beginning of each test session, individuals received two training 238 trials in which the experimenter baited either the left or the right cup - in full view of the subject. 239 This was performed to ensure that the goats recognised that only one cup was baited. In the test 240 trials, the experimenter baited one of the cups out view of the subject and then placed both cups on 241 the sliding board. He then administered one of the following four conditions (Figure $1 \mathrm{e}-\mathrm{h}$ ):

243 Touch: the experimenter touched the baited cup for three seconds

244 Point: the experimenter pointed at the baited cup for three seconds

245 Head only: the experimenter oriented his head towards the baited cup for three seconds

246 Control: the experimenter remained motionless for three seconds

248 After each condition, the experimenter pushed the board toward the grate and the individual was 249 permitted to make a choice. Subjects received six sessions of 14 trials (four trials for each test 250 condition and two trials for the control condition in each session), for a total of 24 trials per test 251 condition and twelve trials for the control condition. We reduced the number of trials in the control 252 condition to avoid potential side biases as reported in the study of Kaminski and colleagues (2005). 253 We reasoned that the lack of information provided by the experimenter in this condition was likely 254 to encourage subjects to follow arbitrary decision rules (such as "always chose left when no 255 information is available”) that would therefore facilitate side preferences. Left and right bowls were 256 baited pseudorandomly with the restriction that no side was baited more than twice consecutively. 


\section{Data coding and statistical analysis}

260

261 Goat behaviour was video-recorded (Panasonic WV-CP500, Tamron 13VG2811ASIR-SQ lens, 262 EverFocus EDRHD-4H4 HDcctv Hybrid DVR). For Experiment 2, the trials were scored live. A 263 “correct” choice was scored if the subject chose the baited cup. The effects of 'condition', 'half' and 264 their interaction on performance (correct and incorrect choices) were modelled using a generalised 265 linear mixed model (PROC GLIMMIX, SAS ${ }^{\circledR}$ 9.2, SAS Institute Inc., Cary, NC, USA) with a 266 binary distribution ( 0 and 1 ) and a logit link function. This procedure can accommodate unbalanced 267 data; in our study, test conditions were presented over 24 trials, and the control condition was 268 presented over 12 trials. Each animal was identified as the subject for the repeated statement and 269 was included with all fixed factors in both models. Least square means (LSM) and their standard 270 errors (SE) were calculated. For pair wise comparisons, post-hoc analysis with adjustments for 271 repeated testing was applied (Tukey-Kramer corrections). For individual data on performance, 272 binomial tests were conducted. If the subjects chose correctly in 18 or more of the 24 trials in a 273 given condition, it was considered as significant $(P=0.023$, two-tailed). 


\section{Results}

278 We found a significant effect of the interaction of 'half' and 'condition' on performance (Figure 3;

$279 F_{3,80}=3.93 ; P=0.011$ ). Post-hoc analysis revealed that subjects performed significantly better in 280 the 'Touch' and 'Point' conditions than in the 'Control' condition in the first half of trials (all $P<$ 281 0.01) and significantly better in the 'Touch' and 'Point' conditions than the 'Head only' and 282 'Control' conditions in the second half of trials (all $P<0.01$ ). We found no significant difference in 283 performance between 'Head only' and 'Control' or between 'Point' and 'Touch'. The factor 'half' 284 had an effect on performance in only the 'Point' condition $(P=0.04)$. Goats exhibited slightly 285 improved performance in this condition across sessions. On an individual level, six subjects 286 performed above the level expected by chance in the 'Touch' condition and ten subjects performed 287 better than expected by chance in the 'Point' condition (see Table 1). No subject exceeded the 288 chance level in either the 'Head only' or 'Control' conditions. 
301 Table 1 Results of Experiment 2. Numbers indicate the percentage of correct choices for each 302 condition- Individual performances exceeding chance level are in bold (binomial test; $\mathrm{P}<0.05$ ).

\begin{tabular}{|c|c|c|c|c|}
\hline & Touch & Point & Gaze & Control \\
\hline Subject & 24 trials & 24 trials & 24 trials & 12 trials \\
\hline 2 & 91.67 & 83.33 & 50.00 & 66.67 \\
\hline 3 & 95.83 & 91.67 & 58.33 & 25.00 \\
\hline 4 & 66.67 & 87.50 & 66.67 & 25.00 \\
\hline 5 & 62.50 & 58.33 & 50.00 & 58.33 \\
\hline 6 & 58.33 & 79.17 & 37.50 & 58.33 \\
\hline 7 & 83.33 & 79.17 & 50.00 & 50.00 \\
\hline 8 & 83.33 & 91.67 & 37.50 & 41.67 \\
\hline 9 & 66.67 & 87.50 & 45.83 & 16.67 \\
\hline 33 & 79.17 & 79.17 & 54.17 & 58.33 \\
\hline 44 & 70.83 & 87.50 & 54.17 & 41.67 \\
\hline 55 & 87.50 & 100.00 & 41.67 & 66.67 \\
\hline Mean & 76.89 & 84.09 & 49.62 & 46.21 \\
\hline SEM & 3.78 & 3.22 & 2.66 & 5.31 \\
\hline
\end{tabular}




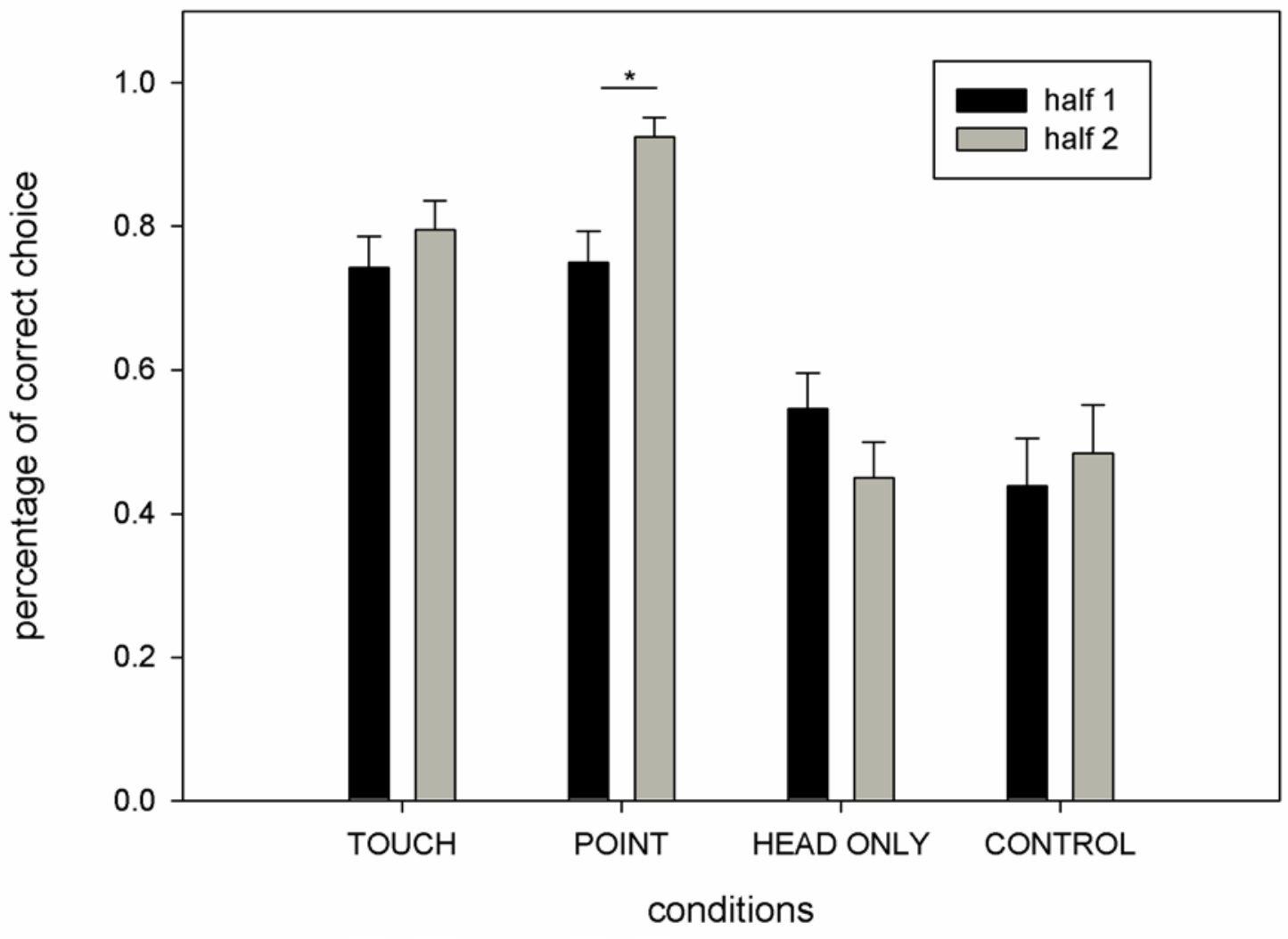

Figure 3

305 Results of Experiment 2. Graph shows the relative performance of subjects in locating a hidden 306 food reward after administering different human-given cues (LSM \pm SE). Asterisk indicates 307 significant differences between the first and second half of trials. 


\section{Discussion}

In Experiment 1, we observed a steady decrease in the active anticipatory behaviour of goats between the 'Control' condition to the 'Out' condition. Anticipatory behaviour depends not only on

314 the past or present experience but also on predictions and expectations about the future (Butz et al. 2003). In the present study, in addition to indicating a subject's sensitivity to the reward, different levels of active anticipation in the subjects suggest differences in their perceptions and processing the various head and body postures of the human experimenter, that latter of which suggest different levels of attention towards the subject. In contrast, goats stood alert for significantly more time when the experimenter was present but not paying attention to the subject ('Head' and 'Back' conditions) relative to the 'Control' and 'Out' conditions. These results indicate that the subjects tailored their behaviour according to the presence or absence of the experimenter in general and the head and body orientation of the experimenter in particular as a means for reward delivery.

In Experiment 2, goats correctly used 'Touch' and 'Point' cues to infer the location of the reward but did not perform better than expected by chance in the 'Head only' and 'Control' conditions. These results therefore mirror those of Kaminski and colleagues (2005). However, in contrast to Kaminski and colleagues (2005), in which the development of a strong side bias was indicated, goat performance in the 'Point' condition increased significantly over time in the present study - indicating that subjects learned to use this gesture to find the hidden reward. As suggested by the data from within individuals, no side bias was evident in the other test conditions, indicating that our subjects' performance at the chance level in the 'Head only' condition was not due to development of a strong side bias, as reported in Kaminski et al. (2005). In contrast to 'Head only' cues, 'Point' and 'Touch' cues involve local and stimulus enhancement effects of the experimenter. As the goats were unable to use cues lacking local enhancement (i.e., head cues), this suggests that 334 they likely do not understand the head direction as a cue (at least innately and without extensive training; see below). This is one of few studies of how non-human animals perceive the head and 
body orientation and communicative cues of humans, using a nearly identical setup in both experiments (but see von Bayern and Emery 2009); it is also one of the first to test non-primate mammals with a design similar to the food-requesting paradigm used previously with greats apes and monkeys (but see Gaunet and Deputte 2011).

From an evolutionary perspective, the ability to detect those individuals that are paying one attention is crucial in intra- (e.g., deception) and inter-specific encounters (e.g., predator avoidance). For goats, as a prey species, this ability may be particularly useful in inter-species encounters (see positive results of Experiment 1). The ability to co-orient one's own gaze into distant space with that of others, as shown by Kaminski and colleagues (2005), is likely an adaptation for predator detection as well. In contrast, using the gaze cues of con- or hetero-specifics that are directed towards food sources may be useful in cooperative and/or competitive contexts. Because food sources for goats are likely abundantly distributed, there is likely no strong adaptive need to share attention with other individuals on particular food sources (see negative results of Experiment 2). These results support the findings of previous research (Baciadonna et al. 2013; Briefer et al. 2014) which showed that goats favoured personal over social information in a foraging task. For horses, which similarly rely on abundant, widely distributed food sources,- no evidence for the use of head cues in an object choice task has been found (Proops et al. 2010; Proops et al. 2013), although they can differentiate among different head and body postures of humans (Proops and McComb 2010; Proops et al. 2013), similar to the goats of the current study. In contrast, species such as dogs (McKinley and Sambrook 2000; Soproni et al. 2001; Hare et al. 2002) and pigs (Nawroth et al. 2014b), which rely more heavily on patchily distributed food sources, have been shown to use head cues in object choice tasks. Other candidate species for testing the effect of species-specific 358 foraging ecology on the use of head direction as communicative cue in a food-related context are 359 sheep and cattle, which both rely on abundant distributed food sources. No studies using object choice tasks in these species are yet available yet. 
362

363

364

changes in the behaviour of non-human primates in response to different human attentive states (Povinelli and Eddy 1996; Maille et al. 2012; Bourjade et al. 2014), spontaneous anticipatory behaviour may be a more informative measure for other non-human animals, especially nonprimates. Thus, anticipatory behaviour may serve as an additional parameter for assessing not only the animal's sensitivity to a reward but also how it perceives the different head and body postures of a human. The observed anticipatory behaviour in Experiment 1 may have involved some understanding of the level of attention the experimenter was paying to the subject during the different test conditions. A higher level of the experimenter's attention may indicate a higher probability of reward delivery, which in turn could increase the active anticipatory behaviour of the test subject. In contrast, a lower level of attention by the experimenter while he is present may indicate a reduced probability of a reward delivery, leading to a subsequent decrease in arousal and increase in the time standing alert. Another, more parsimonious, explanation may be that the behavioural differences between the test conditions and the control condition may reflect a decreased expectation of reward delivery in the test trials that partially or fully did not mirror the position of the experimenter in the instantly rewarded training trials (Gómez 2005b). Goats likely learned that the posture of the experimenter in the training trials (body and head oriented towards subject), together with the cup covering the reward, signalled an immediately impending food delivery. This visual cue was largely absent when the experimenter left the room and differed more ('Body’ condition) or less ('Head' condition) from the 'Control' condition when the experimenter was present. Interestingly, we found no differences in the time spent in active anticipatory behaviour or standing alert between the first and second half of sessions, indicating that no learning took place during the test sessions.

In a study of domestic fowl, the time spent standing alert was slightly greater when subjects anticipated a learned positive outcome, rather than a neutral or negative one, following an acoustic cue (Zimmerman et al. 2011). In our study, subjects only experienced positive outcomes but varied substantially in their extent of standing alert, potentially indicating high sensitivity toward the head 
and body orientation of other subjects. We suggest that this particular behaviour should also be considered in future behavioural studies. For example, this behavioural measure could be included in expectation-of-violation paradigms in non-primate mammals (Müller et al. 2011; Proops and McComb 2012) in which context-depending variation in anticipatory behaviour is expected and parameters such as 'looking time' are difficult to measure due to the lateral eye position of ruminants..The pattern of recorded vocalisations (at least for one subject) in Experiment 1 may indicate attempts to attract the experimenter's attention (Kaminski et al. 2004; Bourjade et al. 2014). However, in light of the lower level of anticipatory behaviour exhibited toward the experimenter, the most likely explanation for the increase in vocalization rate may have been an increase in frustration/distress in the subject. Unfortunately, due to the low number of vocalising individuals, no meaningful analysis was possible. Moreover, no other visual or auditory behavioural indicators of attempts to draw the attention of the experimenter were observed (Bourjade et al. 400 2014). The results of Experiment 1suggest that the subjects acknowledged the presence and absence 401 of the experimenter in general and his head and body orientation in particular as indicators of reward delivery. Future studies should investigate the cognitive mechanisms underlying these discriminatory abilities by focusing on their functional properties under similar test conditions 404 (Flombaum and Santos 2005; von Bayern and Emery 2009). Although we found neither an 405 indication of the subjects' spontaneous use of head direction nor an increase in their performance over time in the 'Head only' condition in Experiment 2, we cannot exclude the possibility that an 407 increase in the number of trials or a more salient presentation of this cue could lead to success, at 408 least in some individuals (Giret et al. 2009; Schmidt et al. 2011). However, an increase in 409 performance over repeated trials would likely be the result of a conditioned response rather than 410 comprehension of the communicative cue.

We conclude that goats can differentiate among the different body postures of a human,

412 including head orientation, and that they can use various physical human cues. However, they fail to 413 spontaneously use human head direction as a cue in a food-related context. 


\section{Acknowledgments}

416

417 We would like to thank Katrin Siebert for data coding, Gerd Nürnberg for statistical advice, and 418 Dieter Sehland and Heinz Deike for excellent technical assistance.

419 
Baciadonna L, McElligott AG, Briefer EF (2013) Goats favour personal over social information in an experimental foraging task. PeerJ 1:e172. doi: 10.7717/peerj.172

Bania AE, Stromberg EE (2013) The effect of body orientation on judgments of human visual attention in western lowland gorillas (Gorilla gorilla gorilla). J Comp Psychol 127:82-90. doi: 10.1037/a0027261

Von Bayern AMP, Emery NJ (2009) Jackdaws respond to human attentional states and communicative cues in different contexts. Curr Biol 19:602-6. doi: 10.1016/j.cub.2009.02.062

Bolles RC (1968) Anticipatory general activity in thirsty rats. J Comp Phys Psych 65:511-513.

Botting JL, Wiper ML, Anderson JR (2011) Brown (Eulemur fulvus) and Ring-Tailed Lemurs (Lemur catta) Use Human Head Orientation as a Cue to Gaze Direction in a Food Choice Task. Folia Primatol 82:165-176. doi: 10.1159/000333142

Bourjade M, Meguerditchian A, Maille A, et al. (2014) Olive baboons, Papio anubis, adjust their visual and auditory intentional gestures to the visual attention of others. Anim Behav 87:121128. doi: 10.1016/j.anbehav.2013.10.019

Bräuer J, Call J, Tomasello M (2005) All great ape species follow gaze to distant locations and around barriers. J Comp Psychol 119:145-54. doi: 10.1037/0735-7036.119.2.145

Briefer EF, Haque S, Baciadonna L, McElligott AG (2014) Goats excel at learning and remembering a highly novel cognitive task. Front Zool 11:20. doi: 10.1186/1742-9994-11-20

Bugnyar T, Stöwe M, Heinrich B (2004) Ravens, Corvus corax, follow gaze direction of humans around obstacles. Proc Biol Sci 271:1331-6. doi: 10.1098/rspb.2004.2738

Bulloch MJ, Boysen ST, Furlong EE (2008) Visual attention and its relation to knowledge states in chimpanzees, Pan troglodytes. Anim Behav 76:1147-1155. doi: 10.1016/j.anbehav.2008.01.033

Butz M V., Sigaud O, Gérard P (2003) Anticipatory Behavior: Exploiting Knowledge About the Future to Improve Current Behavior. Anticip. Behav. Adapt. Learn. Syst. Found. Theor. Syst. Springer, pp 1-10

Craig W (1918) Appetites and aversions as constituents of instincts. Biol Bull 34:91-107.

Davidson GL, Butler S, Fernández-Juricic E, et al. (2014) Gaze sensitivity: function and mechanisms from sensory and cognitive perspectives. Anim Behav 87:3-15. doi: 10.1016/j.anbehav.2013.10.024

Flombaum JI, Santos LR (2005) Rhesus Monkeys Attribute Perceptions to Others. Curr Biol 15:447-452. doi: 10.1016/j.cub.2004.12.076

Gácsi M, Miklosi A, Varga O, et al. (2004) Are readers of our face readers of our minds? Dogs (Canis familiaris) show situation-dependent recognition of human's attention. Anim Cogn 7:144-153. doi: 10.1007/s10071-003-0205-8 
Gaunet F, Deputte BL (2011) Functionally referential and intentional communication in the domestic dog: effects of spatial and social contexts. Anim Cogn 14:849-60. doi: 10.1007/s10071-011-0418-1

Giret N, Miklósi Á, Kreutzer M, Bovet D (2009) Use of experimenter-given cues by African gray parrots (Psittacus erithacus). Anim Cogn 12:1-10. doi: 10.1007/s10071-008-0163-2

Gómez J-C (2005a) Species comparative studies and cognitive development. Trends Cogn Sci 9:118-25. doi: 10.1016/j.tics.2005.01.004

Gómez J-C (2005b) Requesting gestures in captive monkeys and apes: Conditioned responses or referential behaviours? Gesture 5:91-105. doi: 10.1075/gest.5.1.08gom

Hansen SW, Jeppesen LL (2006) Temperament, stereotypies and anticipatory behaviour as measures of welfare in mink. Appl Anim Behav Sci 99:172-182. doi: 10.1016/j.applanim.2005.10.005

Hare B, Brown M, Williamson C, Tomasello M (2002) The domestication of social cognition in dogs. Science 298:1634-6. doi: 10.1126/science.1072702

Hare B, Tomasello M (2005) The emotional reactivity hypothesis and cognitive evolution. Trends Cogn Sci 9:464-465. doi: 10.1016/j.tics.2005.08.010

Hattori Y, Kuroshima H, Fujita K (2007) I know you are not looking at me: capuchin monkeys' (Cebus apella) sensitivity to human attentional states. Anim Cogn 10:141-148. doi: 10.1007/s10071-006-0049-0

Hooks MS, Jones GH, Juncos JL, et al. (1994) Individual differences in schedule-induced and conditioned behaviours. Behav Brain Res 60:199-209.

Imfeld-Mueller S, Hillmann E (2012) Anticipation of a food ball increases short-term activity levels in growing pigs. Appl Anim Behav Sci 137:23-29. doi: 10.1016/j.applanim.2012.01.012

Kaminski J, Call J, Tomasello M (2004) Body orientation and face orientation: two factors controlling apes’ behavior from humans. Anim Cogn 7:216-23. doi: 10.1007/s10071-0040214-2

Kaminski J, Riedel J, Call J, Tomasello M (2005) Domestic goats, Capra hircus, follow gaze direction and use social cues in an object choice task. Anim Behav 69:11-18. doi: 10.1016/j.anbehav.2004.05.008

Loretto M-C, Schloegl C, Bugnyar T (2010) Northern bald ibises follow others' gaze into distant space but not behind barriers. Biol Lett 6:14-7. doi: 10.1098/rsbl.2009.0510

Maille A, Engelhart L, Bourjade M, Blois-Heulin C (2012) To beg, or not to beg? That is the question: mangabeys modify their production of requesting gestures in response to human's attentional states. PLoS One 7:e41197. doi: 10.1371/journal.pone.0041197

Maros K, Gácsi M, Miklósi Á (2008) Comprehension of human pointing gestures in horses (Equus caballus). Anim Cogn 11:457-466. doi: 10.1007/s10071-008-0136-5

McKinley J, Sambrook TD (2000) Use of human-given cues by domestic dogs (Canis familiaris) and horses (Equus caballus). Anim Cogn 3:13-22. doi: 10.1007/s100710050046

Miklósi A, Soproni K (2006) A comparative analysis of animals’ understanding of the human pointing gesture. Anim Cogn 9:81-93. doi: 10.1007/s10071-005-0008-1 
Moe RO, Stubsjøen SM, Bohlin J, et al. (2012) Peripheral temperature drop in response to anticipation and consumption of a signaled palatable reward in laying hens (Gallus domesticus). Physiol Behav 106:527-33. doi: 10.1016/j.physbeh.2012.03.032

Mulcahy NJ, Hedge V (2012) Are great apes tested with an abject object-choice task? Anim Behav 83:313-321. doi: 10.1016/j.anbehav.2011.11.019

Müller C a, Mayer C, Dörrenberg S, et al. (2011) Female but not male dogs respond to a size constancy violation. Biol Lett 7:689-91. doi: 10.1098/rsbl.2011.0287

Nawroth C, von Borell E, Langbein J (2014a) Exclusion Performance in Dwarf Goats (Capra aegagrus hircus) and Sheep (Ovis orientalis aries). PLoS One 9:e93534. doi: 10.1371/journal.pone.0093534

Nawroth C, Ebersbach M, von Borell E (2013) Are juvenile domestic pigs (Sus scrofa domestica) sensitive to the attentive states of humans? - The impact of impulsivity on choice behaviour. Behav Processes 96:53-58. doi: 10.1016/j.beproc.2013.03.002

Nawroth C, Ebersbach M, von Borell E (2014b) Juvenile domestic pigs (Sus scrofa domestica) use human-given cues in an object choice task. Anim Cogn 17:701-713. doi: 10.1007/s10071-0130702-3

Povinelli DJ, Eddy TJ (1996) What young chimpanzees know about seeing. Monogr Soc Res Child Dev 61:1-191.

Proops L, McComb K (2010) Attributing attention: the use of human-given cues by domestic horses (Equus caballus). Anim Cogn 13:197-205. doi: 10.1007/s10071-009-0257-5

Proops L, McComb K (2012) Cross-modal individual recognition in domestic horses (Equus caballus) extends to familiar humans. Proc R Soc B Biol Sci 279:3131-3138. doi: 10.1098/rspb.2012.0626

Proops L, Rayner J, Taylor AM, McComb K (2013) The Responses of Young Domestic Horses to Human-Given Cues. PLoS One 8:e67000. doi: 10.1371/journal.pone.0067000

Proops L, Walton M, McComb K (2010) The use of human-given cues by domestic horses, Equus caballus, during an object choice task. Anim Behav 79:1205-1209. doi: 10.1016/j.anbehav.2010.02.015

Range F, Virányi Z (2011) Development of Gaze Following Abilities in Wolves (Canis Lupus). PLoS One 6:e16888.

Rosati AG, Hare B (2009) Looking past the model species: diversity in gaze-following skills across primates. Curr Opin Neurobiol 19:45-51. doi: 10.1016/j.conb.2009.03.002

Sandel AA, MacLean EL, Hare B (2011) Evidence from four lemur species that ringtailed lemur social cognition converges with that of haplorhine primates. Anim Behav 81:925-931. doi: 10.1016/j.anbehav.2011.01.020

Scheumann M, Call J (2004) The use of experimenter-given cues by South African fur seals (Arctocephalus pusillus). Anim Cogn 7:224-230. doi: 10.1007/s10071-004-0216-0

Schmidt J, Scheid C, Kotrschal K, et al. (2011) Gaze direction: A cue for hidden food in rooks (Corvus frugilegus)? Behav Processes 88:88-93. doi: 10.1016/j.beproc.2011.08.002 
Soproni K, Miklósi Á, Topál J, Csányi V (2001) Comprehension of human communicative signs in pet dogs (Canis familiaris). J Comp Psychol 115:122-126.

Spruijt BM, Van den Bos R, Pijlman FTA (2001) A concept of welfare based on reward evaluating mechanisms in the brain: Anticipatory behaviour as an indicator for the state of reward systems. Appl Anim Behav Sci 72:145-171.

Tempelmann S, Kaminski J, Liebal K (2011) Focus on the essential: all great apes know when others are being attentive. Anim Cogn 14:433-439. doi: 10.1007/s10071-011-0378-5

Tomasello M, Call J, Hare B (1998) Five primate species follow the visual gaze of conspecifics. Anim Behav 55:1063-1069.

Udell M a. R, Dorey NR, Wynne CDL (2008) Wolves outperform dogs in following human social cues. Anim Behav 76:1767-1773. doi: 10.1016/j.anbehav.2008.07.028

Wilkinson A, Mandl I, Bugnyar T, Huber L (2010) Gaze following in the red-footed tortoise (Geochelone carbonaria). Anim Cogn 13:765-769. doi: 10.1007/s10071-010-0320-2

Zimmerman PH, Buijs S a. F, Bolhuis JE, Keeling LJ (2011) Behaviour of domestic fowl in anticipation of positive and negative stimuli. Anim Behav 81:569-577. doi: 10.1016/j.anbehav.2010.11.028 